\title{
A survey into the respiratory effects of prolonged exposure to pulverised fuel ash
}

\author{
C J SCHILLING,' I P TAMS, ${ }^{2}$ R S F SCHILling, ${ }^{3}$ A NEVITT, ${ }^{4}$ C E ROSSITER, ${ }^{3}$ \\ B WILKINSON
}

From the Medical Branch Central Electricity Generating Board (CEGB South Eastern Region (SER)), Central Toxicology Laboratory, Imperial Chemical Industries PLC, Alderley Park, Macclesfield, Cheshire SK10 4TJ, London School of Hygiene and Tropical Medicine, ${ }^{3}$ London, Central Medical Group Imperial Chemical Industries PLC, ${ }^{4}$ Alderley Park, Macclesfield, Cheshire SK10 4TJ, and Scientific Services Department CEGB, SER, Gravesend, Kent DA12 2RS, UK

\begin{abstract}
Previous studies of respiratory disorders in workers exposed to pulverised fuel ash (PFA) have been confined to radiological effects that were found to be minimal. The present survey included 268 men (88\% of the defined population) with a history of more than 10 years exposure to PFA in six power stations in the south east of England. Respiratory questionnaires with full occupational histories were obtained from all of these subjects, of whom 207 were actively employed and 61 had retired; 243 had lung function tests and 208 had chest $x$ ray examinations. The men were grouped, using their occupational histories, into high, medium, and low exposure categories. Dust concentrations were obtained by personal sampling on a representative sample of men from the three exposure categories. Lung function tests showed that a modest effect on forced vital capacity, vital capacity, forced expiratory volume in one second, peak flow, and gas transfer (DCO) was associated with prolonged heavy exposure to PFA. The men with prolonged heavy exposure also showed higher prevalences of respiratory symptoms. No definite relation between exposure and $x$ ray changes was established. The results of this cross sectional survey indicate that exposures to PFA should not exceed the limits recommended by the Health and Safety Executive for low toxicity dusts.
\end{abstract}

About 12 million tonnes a year of pulverised fuel ash (PFA) are produced by the Central Electricity Generating Board (CEGB) from burning about 70 million tons of pulverised coal. PFA contains $60-80 \%$ insoluble glass particles and $2-4 \%$ soluble material. The insoluble crystalline residue of about $15-30 \%$ consists mainly of mullite, magnetite, carbon, and quartz. ${ }^{\prime}$ The quartz content of PFA varies between $1 \%$ and $9 \%$ but the evidence suggests that its toxicity is reduced by the high combustion temperature. ${ }^{2}$ Trace elements such as arsenic, barium, boron, chromium, copper, lead, manganese, and nickel are present in ash in concentrations around $100 \mathrm{ppm}$ by weight.

Pulverised coal is blown into boilers to be burnt and the resulting ash is removed by electrostatic precipitators or, in some cases, cyclones, and collected in hoppers for disposal.

About one third of the total ash produced is sold commercially for use as a material in the building and

Accepted 16 November 1987 road construction industries. A particular use is in the manufacture of breeze blocks.

PFA is not cytotoxic. ${ }^{34}$ The exposure of laboratory animals to PFA has not shown any appreciable effects on the respiratory tract. ${ }^{56}$ Radiological surveys of employees of the CEGB have shown significant effects attributable directly to CEGB employment in only four $(1.5 \%)$ cases. ${ }^{7}$ There are, however, no published reports of epidemiological surveys of the effects of exposure to PFA which have included investigations of respiratory symptoms, lung function, and chest radiology. The objective of this study was to determine exposure to PFA.

\section{Materials and methods}

STUDY POPULATION

The study population was exclusively male and consisted of:

(1) Boiler cleaners, ash plant attendants, fitters (electrical and mechanical), unit adjusters, and turbine the effects on the respiratory system of long term 
Table 1 Distribution of age, height, and weight by station

\begin{tabular}{lclll}
\hline Site & $\begin{array}{l}\text { No in } \\
\text { study }\end{array}$ & $\begin{array}{l}\text { Age } \\
\text { mean (range) }\end{array}$ & $\begin{array}{l}\text { Height } \\
\text { mean (range) }\end{array}$ & $\begin{array}{l}\text { Weight } \\
\text { mean (range) }\end{array}$ \\
\hline A & 63 & $54(32-69)$ & $173 \cdot 3(160-187)$ & $81 \cdot 0(50-111)$ \\
B & 51 & $55(32-71)$ & $173.4(164-186)$ & $79 \cdot 0(57-107)$ \\
C & 26 & $61(40-72)$ & $171 \cdot 5(156-186)$ & $77.4(58-92)$ \\
D & 40 & $55(35-74)$ & $173.9(153-184)$ & $83 \cdot 7(67-108)$ \\
E & 34 & $47(26-65)$ & $175.9(162-193)$ & $80 \cdot 1(65-112)$ \\
F & 29 & $53(39-69)$ & $172.9(159-184)$ & $80 \cdot 1(55-109)$ \\
Total & 243 & & & \\
\hline
\end{tabular}

operators who had worked for 10 years or more in coal fired power stations in the south eastern region of the CEGB.

(2) All retired employees who had worked for 10 years or more as boiler cleaners, ash plant attendants, and turbine operators.

All subjects were or had been employed at one of six coal fired power stations in the south eastern region of the CEGB. The number of active employees meeting these criteria was 233 and the number who had retired 71 , giving a total study population of 304 , of whom $277(91 \%)$ agreed to participate. Of these, 25 did not attend for any further tests; six were non-white caucasian and three had an exposure history of less than 10 years. The numbers who participated were 207 employees and 61 retirees, respectively $89 \%$ and $86 \%$ of defined populations. Respiratory questionnaires with full occupational histories were obtained on all 268 subjects; $243(79 \%)$ had lung function tests and $208(68 \%)$ chest $x$ ray examinations. Forty of the 68 subjects without $x$ ray data were retired and unavailable. Table 1 gives the demographic data for the study group of 243 subjects.

\section{CATEGORISATION OF EMPLOYEES INTO EXPOSURE GROUPS}

The occupational history of each employee was used to assign each individual to one of the following categories.

\section{High}

Boiler cleaners and ash plant attendants subdivided as follows:

(a) 20 or more years,

(b) less than 20 but more than 10 years.

Those with less than 10 years exposure in this group but at least 10 years altogether in power stations were assigned to the medium category.

\section{Medium}

Electrical and mechanical fitters and unit adjusters with 10 or more years experience in this group.

Low

Less than 10 years experience in the medium group.
Ten years or more as turbine operators.

Some turbine operators described regular duties on jobs involving heavy exposure to PFA. Those with 10 or more years experience of these duties were ascribed to the medium group.

\section{EXPOSURE MEASUREMENTS}

Personal shift exposures were obtained during the period of the survey on a representative sample of the three exposure categories (A Wilkinson, CEGB internal report SER/SSD/84/0074/N. OHC45.) Sixty personal shift samples per station were taken: 30 for the high exposure group, 20 for the medium, and 10 for the low. This weighting was adopted because the higher exposure groups were likely to have greater variability.

\section{QUESTIONNAIRE}

A modified Medical Research Council (MRC) questionnaire was administered to each subject. Modifications included questions to determine the relation between symptoms on rest days, holidays, and workdays. Three named interviewers administered the questionnaire; CJS and RSFS to current employees who were allocated on a random basis and IPT all the retired subjects. A full occupational history was also taken after the questionnaire had been completed.

\section{LUNG FUNCTION TESTS}

Tests on each worker were performed once only during their shift. These were carried out using the mobile lung function unit of Imperial Chemical Industries plc.

A Hewlett-Packard 47804S pulmonary calculator system was used to measure variables of ventilation and gas exchange.

This system uses pneumotachographs to measure flow rates and volumes. A Fleisch No 3 pneumotachograph was used to measure forced expiratory flow rates. This device had a linearity of $0.3 \mathrm{l} / \mathrm{sec}$ at a flow of $10 \mathrm{l} / \mathrm{sec}$. A Fleisch No 2 pneumotachograph was used to measure volume in the measurement of gas transfer and this had a linearity of $0.121 / \mathrm{sec}$ at a flow of $4.0 \mathrm{l} / \mathrm{sec}$. These instruments have been found to meet the performance criteria of the American Thoracic Society. ${ }^{8}$

A thermal conductivity analyser was used to measure Helium (He) concentration and had a range of $0-11 \% \mathrm{He}$ and an accuracy of $\pm 1.0 \%$. Carbon monoxide (CO) was measured by an electrolytic device with a range of $0-0.33 \% \mathrm{CO}$ and an accuracy of \pm $2 \cdot 5 \%$.

These instruments were linked to a Hewlett Packard 9825T desktop calculator via a 16 bit analogue-todigital converter. Data were displayed on a visual display unit for evaluation.

The pneumotachographs were calibrated for volume twice daily using a 1.51 syringe. Calibration 
was successful when each of three successive passes of the syringe yielded results of $1.50 \pm 0.01 \mathrm{l}$. The $\mathrm{He}$ and $\mathrm{CO}$ analysers were calibrated before each test using a gas mixture comprising $0.3 \% \mathrm{CO}, 10 \% \mathrm{He}, 21 \%$ oxygen, and $68.7 \%$ nitrogen (British Oxygen Company, London). Each analyser displayed relative concentration and these were set to $100 \pm 0.2 \%$ at calibration.

\section{VENTILATION MEASUREMENTS}

A minimum of three maximal expiratory flow volume (MEFV) curves were collected from each subject. Acceptable curves showed no initial hesitation, a rapid rise to peak flow (PF), complete expiration to residual volume, and yielded values of forced vital capacity (FVC) within 5\% of the highest. ${ }^{9}$ A rest period of at least one minute was allowed between successive forced expirations. Flow rate variables were taken from the curve with the highest value of PF and forced expiratory volume in one second $\left(\mathrm{FEV}_{1}\right)$. These variables were forced expiratory flow between $25 \%$ and $75 \%$ of FVC $\left(\right.$ FEF $\left._{25-75 \%}\right)$, maximum expiratory flow when $50 \%$ and when $25 \%$ of FVC remains to be expired $\left(\mathrm{MEF}_{50 \%}\right.$ and $\left.\mathrm{MEF}_{25 \%}\right) \mathrm{PF}, \mathrm{FEV}_{1}, \mathrm{FVC}$, and FEV $_{1} /$ FVC\%.

\section{Gas transfer}

One single breath manoeuvre was used to determine gas transfer (DCO). ${ }^{10}$

\section{Data collection}

Data were stored on a floppy disk on a Superbrain QD micro computer linked to the H-P $9825 \mathrm{~T}$ by a second IEEE bus and later transferred to an IBM 3081 mainframe computer via the telephone network.

\section{CHEST RADIOLOGY}

Full sized posterioranterior chest $x$ ray films were taken by the National Coal Board (NCB) $x$ ray unit. The $x$ ray films were mixed with $20 x$ ray films of NCB employees who were known not to have been exposed to dust. These were read blind in randomised order by three experienced readers according to the Inter- national Labour Office's international classification of radiographs of pneumoconiosis. ${ }^{\text {" }}$

From these readings a median reading was determined for subsequent analyses. The median reading was the middle reading for each feature of the classification. Thus readings of small opacity categories of $0 / 0,0 / 1$, and $1 / 1$ were recorded as a median reading of $0 / 1$. It follows that if any two readers agreed that a particular abnormality was present then that would have been recorded as positive on the median reading.

The profusion of small opacities was recorded separately for rounded and irregular shapes. Frequently there was disagreement over the shape and so the median was only calculated for combined small opacities, in line with the 1980 revision of the ILO classification. The shape/size median was determined by taking into account the separate readings for rounded and irregular opacities, using the higher profusion score to resolve any disagreements.

\section{STATISTICAL METHODOLOGY (LUNG FUNCTION)}

Stepwise multiple linear regression analyses were carried out on each lung function variable with age, height, weight, smoking status, and exposure acting as explanatory variables. An age/smoking interaction term was also incorporated in the model.

\section{STATISTICAL TECHNIQUES ( $x$ RAYS)}

To investigate the relation between the median $x$ ray readings, age, and the indices of the exposure (exposure group and duration, previous exposure to dust in another job, and exposure to asbestos), cross tabulations were first made of the numbers in each possible subgroup together with the prevalences of the abnormality to be analysed.

The prevalences were then related to age group, exposure group, smoking habit, previous exposures to dust, and exposure to asbestos using logistic regression. This technique is similar to multiple regression, except that the logit transformation is used to transform the prevalence rates as analysis of untransformed prevalences by regression techniques is not valid.

Table 2 Sampling results for total dust for all exposure groups and by station

\begin{tabular}{|c|c|c|c|c|c|c|c|c|c|c|c|c|c|}
\hline \multirow[b]{2}{*}{ Station } & \multicolumn{4}{|c|}{ Low exposure $\left(\mathrm{mg} / \mathrm{m}^{3}\right)$} & \multicolumn{4}{|c|}{ Medium exposure $\left(\mathrm{mg} / \mathrm{m}^{3}\right)$} & \multicolumn{4}{|c|}{ High exposure $\left(\mathrm{mg} / \mathrm{m}^{3}\right)$} & \multirow{2}{*}{$\begin{array}{l}\text { Samples taken } \\
\text { with stations } \\
\text { on load }(\%)\end{array}$} \\
\hline & No & $\overline{\boldsymbol{x}}$ & $S D$ & Range & No & $\bar{x}$ & $S D$ & Range & No & $\bar{x}$ & $S D$ & Range & \\
\hline $\begin{array}{l}\mathbf{A} \\
\mathbf{B} \\
\mathbf{C} \\
\mathbf{E} \\
\mathbf{F}\end{array}$ & $\begin{array}{r}7 \\
10 \\
21 \\
9 \\
9\end{array}$ & $\begin{array}{l}1.61 \\
1.45 \\
3.65 \\
1.55 \\
2.76\end{array}$ & $\begin{array}{l}1 \cdot 11 \\
2 \cdot 17 \\
6 \cdot 29 \\
1 \cdot 44 \\
3 \cdot 17\end{array}$ & $\begin{array}{l}0.13-3.5 \\
0.27-7.07 \\
0.08-21.8 \\
0.13-4.74 \\
0.33-9.35\end{array}$ & $\begin{array}{l}20 \\
16 \\
\frac{19}{22}\end{array}$ & $\begin{array}{l}5 \cdot 13 \\
4 \cdot 68 \\
- \\
3 \cdot 74 \\
9 \cdot 39\end{array}$ & $\begin{array}{l}7.64 \\
6.57 \\
-10.95 \\
15.78\end{array}$ & $\begin{array}{l}0.12-35.63 \\
0.75-21.33 \\
\overline{0} \\
0.23-48.82 \\
0.63-73.31\end{array}$ & $\begin{array}{l}18 \\
30 \\
24 \\
26 \\
25\end{array}$ & $\begin{array}{r}1 \cdot 22 \\
13.45 \\
8.09 \\
6 \cdot 13 \\
12.63\end{array}$ & $\begin{array}{r}1 \cdot 47 \\
23 \cdot 75 \\
19 \cdot 86 \\
7 \cdot 72 \\
14 \cdot 50\end{array}$ & $\begin{array}{l}0.20-6.48 \\
0.07-98.62 \\
0 \cdot 13-74.49 \\
0.38-34.72 \\
0.57-57.45\end{array}$ & $\begin{array}{r}22 \\
80 \\
100 \\
97 \\
100\end{array}$ \\
\hline All results & 56 & $2 \cdot 52$ & $4 \cdot 25$ & $0.08-21 \cdot 8$ & 78 & $5 \cdot 87$ & $11 \cdot 13$ & $0 \cdot 12-73 \cdot 31$ & 123 & $8 \cdot 26$ & $16 \cdot 72$ & $0.07-98 \cdot 62$ & $78 \cdot 2$ \\
\hline
\end{tabular}


Table 3 Respiratory effects of prolonged exposure to pulverised fuel ash: questionnaire responses

\begin{tabular}{|c|c|c|c|c|c|c|c|}
\hline \multirow[b]{2}{*}{ Study population } & \multirow[b]{2}{*}{ Non-smokers } & \multirow[b]{2}{*}{ Ex-smokers } & \multirow{2}{*}{$\begin{array}{l}\text { Current } \\
\text { smokers }\end{array}$} & \multirow{2}{*}{$\begin{array}{l}\text { Low } \\
\text { exposure }\end{array}$} & \multirow{2}{*}{$\begin{array}{l}\text { Medium } \\
\text { exposure }\end{array}$} & \multicolumn{2}{|c|}{ High exposure } \\
\hline & & & & & & $<20$ & $\geqslant 20$ \\
\hline \multirow[t]{2}{*}{$\begin{array}{l}\text { No } \\
\text { Chronic cough } \\
\text { Chronic phlegm } \\
\text { Dypsnoea grade >2 } \\
\text { Work related dypsnoea } \\
\text { Regular wheeze } \\
\text { Dypsnoea and wheeze } \\
\text { Work related wheeze } \\
\text { Chest tightness } \\
\text { Work related chest } \\
\text { tightness }\end{array}$} & $\begin{array}{r}37 \\
19 \% \\
22 \% \\
24 \% \\
3 \% \\
11 \% \\
16 \% \\
3 \% \\
22 \%\end{array}$ & $\begin{array}{r}107 \\
15 \% \\
17 \% \\
35 \% \\
9 \% \\
9 \% \\
15 \% \\
7 \% \\
22 \%\end{array}$ & $\begin{array}{r}99 \\
32 \% \\
26 \% \\
27 \% \\
2 \% \\
17 \% \\
11 \% \\
9 \% \\
20 \%\end{array}$ & $\begin{array}{r}58 \\
17 \% \\
22 \% \\
29 \% \\
5 \% \\
9 \% \\
7 \% \\
3 \% \\
21 \% \\
21 \%\end{array}$ & $\begin{array}{r}121 \\
23 \% \\
18 \% \\
22 \% \\
6 \% \\
12 \% \\
11 \% \\
8 \% \\
18 \%\end{array}$ & $\begin{array}{l}35 \\
11 \% \\
23 \% \\
37 \% \\
6 \% \\
11 \% \\
17 \% \\
11 \% \\
26 \%\end{array}$ & $\begin{array}{l}29 \\
45 \% \\
31 \% \\
59 \% \\
3 \% \\
28 \% \\
35 \% \\
3 \% \\
31 \%\end{array}$ \\
\hline & $5 \%$ & $8 \%$ & $3 \%$ & $2 \%$ & $7 \%$ & $11 \%$ & $0 \%$ \\
\hline
\end{tabular}

\section{Results}

\section{EXPOSURE MEASUREMENTS}

Table 2 shows the results for total dust exposure for all groups by power station. Technical problems were encountered at one power station and the measurements were unsatisfactory; for this reason they are not shown on table 2 . Those for $A$ and $C$ were not representative since these stations were closing and the duties of the various categories of staff did not conform to practices obtaining during the major part of the lifetime of the station.

The results for the more representative stations (B, E, and F) show a relation between the low exposure, medium exposure, and high exposure groups that approximates to a ratio of $1: 2: 3$.

\section{RESPIRATORY SYMPTOMS QUESTIONNAIRE}

Table 3 lists the responses to several sections of the questionnaire by smoking habit and exposure group. Dyspnoea was assessed using the grading system of Fletcher. ${ }^{12}$ Current smokers showed a higher prevalence than non-smokers and ex-smokers of chronic cough, chronic phlegm, regular wheeze, and work related wheeze. Those in the high exposure (greater than 20 years) group showed a higher prevalence of chronic cough, chronic phlegm, dysp- noea grade $>2$, regular wheeze, dyspnoea and wheeze, and wheeze and chest tightness compared with all the other groups. The work related symptoms showed no definite trends with exposure. Table 4 shows that there were relatively few non-smokers and ex-smokers in the high exposure groups and this should be taken into account when interpreting these data.

\section{LUNG FUNCTION TESTS}

To assess the effect of exposure on lung function, a multiple linear regression analysis using exposure as one of the predictor variables was applied to all the lung function data.

The mean total dust concentration for the high exposure group is roughly three times that of the low exposure group; the corresponding increase for the medium exposure group is twofold (see table 2). Thus exposure was treated quantitatively by arbitrarily ascribing a figure of 1 to the low exposure group and figures of 2,3 , and 4 respectively to the medium, high (less than 20 years), and high (more than 20 years) groups. The variables affected significantly were PVC, PF, VC, and DCO. The remaining four variables $\left(\mathrm{FEV}_{1}, \mathrm{FEV}_{1} / \mathrm{FVC} \%, \mathrm{FEF}_{25-75 \%}, \mathrm{MEF}_{50 \%, 25 \%}\right)$ had a negative coefficient, establishing that the exposure effect was in the same direction for all responses (table 5).

Table 4 Distribution of symptoms of 243 individuals by smoking and exposure groups

\begin{tabular}{|c|c|c|c|c|c|c|c|c|c|c|c|c|}
\hline \multirow[b]{2}{*}{ Symptom } & \multicolumn{4}{|c|}{ Non-smoker } & \multicolumn{4}{|c|}{ Ex-smoker } & \multicolumn{4}{|c|}{ Smoker } \\
\hline & Low & Medium & $\begin{array}{l}\text { High } \\
(<20)\end{array}$ & $\begin{array}{l}\text { High } \\
(\geqslant 20)\end{array}$ & Low & Medium & $\begin{array}{l}\text { High } \\
(<20)\end{array}$ & $\begin{array}{l}\text { High } \\
(\geqslant 20)\end{array}$ & Low & Medium & $\begin{array}{l}\text { High } \\
(<20)\end{array}$ & $\begin{array}{l}\text { High } \\
(\geqslant 20)\end{array}$ \\
\hline $\begin{array}{l}\text { Cough } \\
\text { Phlegm } \\
\text { Dypsnoea } \\
\text { Regular wheezing } \\
\text { Chest tightness } \\
\text { No in each group }\end{array}$ & $\begin{array}{l}2 \\
3 \\
0 \\
0 \\
2 \\
7\end{array}$ & $\begin{array}{r}4 \\
4 \\
5 \\
3 \\
4 \\
21\end{array}$ & $\begin{array}{l}1 \\
1 \\
2 \\
0 \\
1 \\
5\end{array}$ & $\begin{array}{l}0 \\
0 \\
2 \\
1 \\
1 \\
4\end{array}$ & $\begin{array}{r}2 \\
4 \\
11 \\
1 \\
6 \\
29\end{array}$ & $\begin{array}{r}8 \\
7 \\
13 \\
4 \\
11 \\
55\end{array}$ & $\begin{array}{r}2 \\
5 \\
6 \\
2 \\
4 \\
11\end{array}$ & $\begin{array}{r}4 \\
2 \\
7 \\
3 \\
3 \\
12\end{array}$ & $\begin{array}{r}6 \\
6 \\
6 \\
4 \\
4 \\
22\end{array}$ & $\begin{array}{r}16 \\
11 \\
8 \\
7 \\
7 \\
45\end{array}$ & $\begin{array}{r}1 \\
2 \\
5 \\
2 \\
4 \\
19\end{array}$ & $\begin{array}{r}9 \\
7 \\
8 \\
4 \\
5 \\
13\end{array}$ \\
\hline
\end{tabular}


Table 5 Analysis on individuals with lung function and questionnaire results

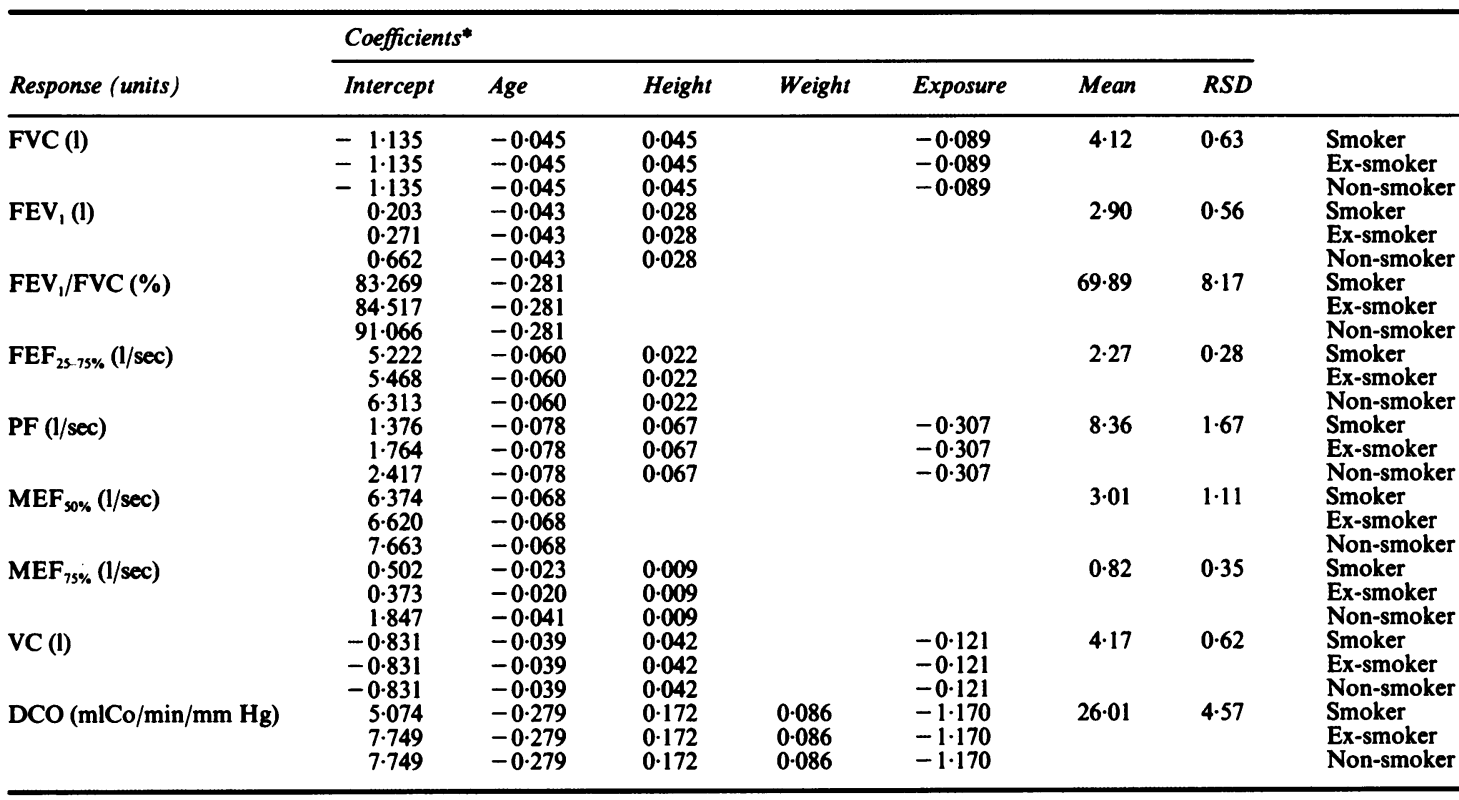

* $\mathrm{p}<0.05$ for all coefficients.

Exposure = 1 if low, 2 if medium, 3 if high (less than 20 years), 4 if high (20 years or more).

When exposure was treated as a qualitative variable the only significant regression coefficient was for DCO in the high exposure group (greater than 20 years).

Smoking habit was shown to influence significantly all variables except FVC and VC. Ex-smokers were generally more adversely affected than smokers. For DCO only smokers showed a significant effect.

An occupational history of exposure to asbestos was not associated with any significant effects on the variables of lung function.

Table 6 shows the lung function results standardised for a man aged 50 and $175 \mathrm{~cm}$ tall. This highlights the significant effects of exposure upon FVC, VC, PF, and DCO shown in table 5 .

\section{CHEST RADIOLOGY}

$x$ Ray readings were obtained for 208 men. Table 7 shows how these men are distributed with respect to the four exposure categories.

A much higher proportion of the more heavily exposed workers did not have an $x$ ray examination because most had retired and were unavailable.

\section{Small opacities}

Table 8 gives the distribution of small opacities. The overall prevalence of any change is $15 \%$ with $9 \%$ of category $0 / 1$ or more. Most of these opacities were of irregular shape and occurred most often among the smokers (table 9).

Table 6 Lung function test results standardised for a man aged 50 and $175 \mathrm{~cm}$ tall

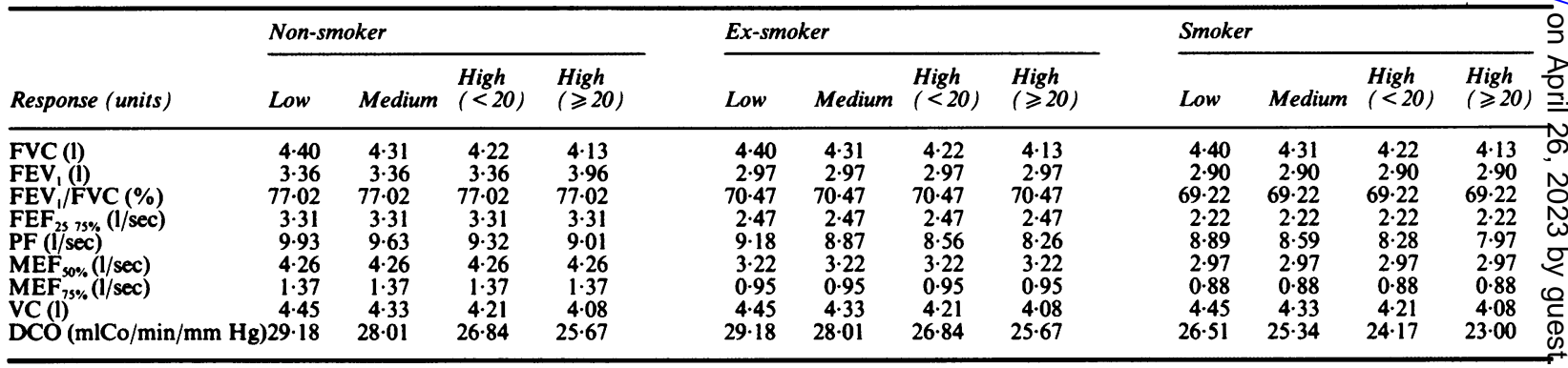


Table 7 Number of men in the $x$ ray and exposure groups (Men aged $\geqslant 65$ in parentheses)

\begin{tabular}{lclc}
\hline Exposure group & With $\times$ ray & No $x$ ray & Total \\
\hline High $(>20$ years) & $16(1)$ & 13 & 29 \\
High (<20 years) & $30(1)$ & 12 & 42 \\
Medium & $109(4)$ & 14 & 123 \\
Low & $53(2)$ & 21 & 74 \\
Total & 208 & 60 & 268 \\
\hline
\end{tabular}

The logistic analysis showed that the prevalence of small opacities of category $1 / 0$ or more was associated but not significantly with exposure group (chisquared $=5.80$ with 3 degrees of freedom $p=0.12$ ) and with smoking (chi-squared $=3.11$ with 2 degrees of freedom $p=0.21$ ) and to a lesser degree with age group (chi-squared $=4.59$ with 4 degrees of freedom $\mathrm{p}=0.33$ ).

Based on the logistic regression coefficient for the prevalence of small opacities of category $1 / 0$ the figure shows how the prevalence varied with exposure group and smoking for men aged 55-64 who represented $42 \%$ of those who underwent $x$ ray examination (see table 10). Although the coefficients differed significantly from zero at the $5 \%$ level, this shows the relative importance of exposure and smoking on the prevalence of small opacities. The highest fitted rates occurred for those men with high exposure for less than 20 years; indeed seven of the 31 men $(23 \%)$ in this group showed such an abnormality compared with $11 \%$ among the remainder.

Of these seven men, five were current smokers and two ex-smokers. One had a history of pulmonary tuberculosis and one of pulmonary embolism. Three men had occupational histories of exposure to dust before joining the CEGB - one as a coal face worker, one as a tiler, and one as a stoker in coal fired ships. Of the two men without medical and occupational histories that might have contributed to their $x$ ray changes, one had worked for 17 years as an ash plant attendant smoking 10 cigarettes a day and the other 18 years as a boiler cleaner smoking two ounces of tobacco a week.

Compared with category $1 / 0$ or more, the prevalence of category $0 / 1$ or more was not as strongly

Table 8 Distribution of readings of small opacities by shape of opacity

\begin{tabular}{llcr}
\hline Reading & Rounded & Irregular & Total \\
\hline $0 / 0$ & & & $177(85 \cdot 1 \%)$ \\
$0 / 1$ & 4 & 8 & $12(5 \cdot 8 \%)$ \\
$1 / 0$ & 0 & 9 & $9(4 \cdot 3 \%)$ \\
$1 / 1$ & 1 & 8 & $9(4 \cdot 3 \%)$ \\
$1 / 2$ & 1 & 0 & 1 \\
Total & 6 & 24 & 208 \\
\hline
\end{tabular}

Table 9 Distribution of readings of small opacities by smoking habits

\begin{tabular}{lcccc}
\hline & Non-smoker & Ex-smoker & Smoker & All groups \\
\hline $0 / 0$ & $29(88 \%)$ & $82(89 \%)$ & $66(80 \%)$ & 177 \\
$0 / 1$ & $3(9 \%)$ & $2(2 \%)$ & $7(8 \%)$ & 12 \\
$1 / 0$ & $1(3 \%)$ & $4(4 \%)$ & $4(5 \%)$ & 9 \\
$1 / 1$ & $0-$ & $4(4 \%)$ & $5(6 \%)$ & 9 \\
$1 / 2$ & $0-$ & $0-$ & $1(1 \%)$ & 1 \\
Total & $33(12 \%)$ & $92(10 \%)$ & $83(20 \%)$ & 208 \\
\hline
\end{tabular}

associated with exposure as with smoking, nor was there a pronounced association with age. This result is not unexpected since irregular small opacities of category $0 / 1$ are particularly associated with smoking and the analysis confirms that the smokers have a higher prevalence of any small opacities than the exsmokers or the non-smokers.

A history of exposure to dusts before employment in the CEGB and to asbestos was not significantly related to the prevalence of small opacities.

\section{Pleural thickening}

The prevalence of pleural thickening was strongly related to age (chi-squared $=13.32$ with 4 degrees of freedom; $p<0.01$ ), as shown in table 9, but to none of the indices of exposure, nor to smoking. Below age 45 , only one man had pleural thickening compared with one in five of those above that age. Four of the 19 retired workers $(21 \%)$ had pleural thickening.

\section{Pleural calcification}

Table 11 shows the pronounced relation between pleural calcification and exposure to asbestos. Altogether only eight men had pleural calcification and five of them had also had exposure to asbestos. No other index of exposure was predictive of pleural calcification.

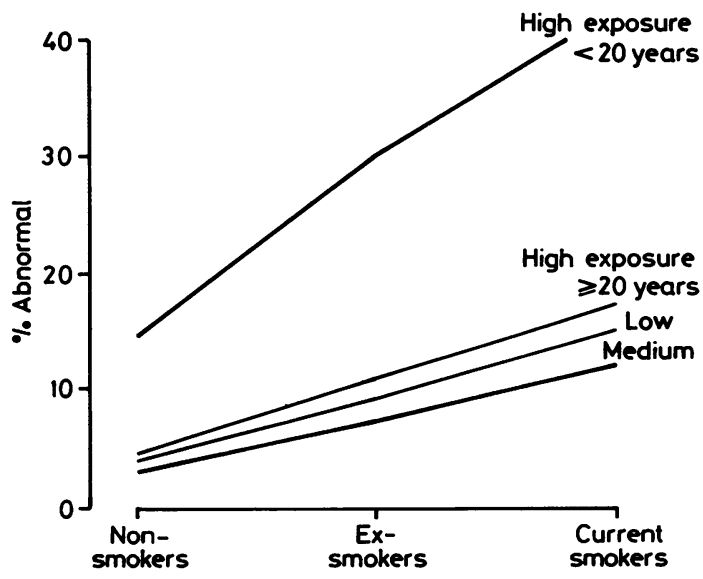

Small opacities $1 / 0$ or more. Men aged 55-64: relation to exposure group and smoking. 
Table 10 Prevalence of pleural thickening

\begin{tabular}{lcr}
\hline & \multicolumn{2}{l}{ Pleural thickening } \\
\cline { 2 - 3 } Age & No & No (\%) \\
\hline $25-34$ & 5 & 0 \\
$35-44$ & 45 & $1(2 \cdot 2 \%)$ \\
$45-54$ & 63 & $12(19 \cdot 0 \%)$ \\
$55-64$ & 87 & $19(21 \cdot 8 \%)$ \\
$65-74$ & 8 & $2(25 \cdot 0 \%)$ \\
Total & 208 & $34(16 \cdot 3 \%)$ \\
\hline
\end{tabular}

\section{Discussion}

There was no evidence to suggest that the group of 27 individuals who refused to participate in the study biased the results with respect to work related effects. The age structure and job distribution of this group were similar to those of the study population. The small group of 25 without, or with incomplete, lung function data contained a higher proportion of individuals with a history of low exposure to PFA and fewer with a history of medium exposure. There was no suggestion that the exclusion of these individuals introduced any bias into the results of the lung function tests and questionnaires. Symptoms of wheeze, dyspnoea, and chest tightness that were interpreted to be related to work did not show a definite trend with exposure; the prevalences of these symptoms were highest in the high exposure ( 20 years duration) group. A recent case report showed PFA to be a cause of occupational asthma. ${ }^{13}$ Further investigations would be required to determine whether the reported symptoms were related to occupational asthma.

As exposure to PFA increases, an increasing effect on FVC and DCO was shown as was an effect of exposure on PF and VC. These findings were confirmed by the multiple regression analysis when exposure was treated as a quantitative variable. When exposure was treated as a qualitative variable the effect of exposure was significant for DCO alone and only in

Table 11 Relation between pleural calcification, exposure to asbestos, and age

\begin{tabular}{|c|c|c|c|c|}
\hline \multirow[b]{3}{*}{ Age } & \multicolumn{4}{|c|}{ Proportion with pleural calcification } \\
\hline & \multicolumn{2}{|c|}{ Asbestos exposed } & \multicolumn{2}{|c|}{ Not asbestos exposed } \\
\hline & No & Proportion & No & Proportion \\
\hline $\begin{array}{l}25-34 \\
35-44 \\
45-54 \\
55-64 \\
65-74\end{array}$ & $\begin{array}{r}1 \\
16 \\
16 \\
18 \\
0\end{array}$ & $\begin{array}{l}0 \% \\
0 \% \\
12 \% \\
17 \% \\
-\end{array}$ & $\begin{array}{r}4 \\
29 \\
47 \\
69 \\
8\end{array}$ & $\begin{array}{l}0 \% \\
0 \% \\
2 \% \\
3 \% \\
0 \%\end{array}$ \\
\hline Total & 51 & $10 \%$ & 157 & $2 \%$ \\
\hline
\end{tabular}

the high exposure (greater than 20 years) group. This suggests that the effect of exposure on lung function is slight and is related to long term heavy exposure. The variables of small airway function showed no relation with exposure.

Quantification of the effects of smoking is difficult because only $15 \%$ of subjects were lifelong nonsmokers. Respiratory symptoms were related to smoking and to exposure but for the latter only in the high exposure group with more than 20 years experience; the inference is that exposure has an effect when it is high and prolonged.

The prevalence of small opacities on $x$ ray films was related to smoking and exposure, in particular in the high exposure group with less than 20 years experience. This group had a high proportion of factors such as smoking, medical conditions, and previous exposure to dust which might have accounted for the high prevalence of $x$ ray changes. This relation was not shown to a significant degree in the high exposure group with greater than 20 years experience. A large proportion of these employees did not undergo $x$ ray examination because they had retired and were not available. Those who had not retired were a survivor population, the development in whom of small opacities for whatever reason may have been associated with leaving this employment.

The findings of this survey taken together suggest an effect of prolonged heavy exposure to PFA. A definite relation has been shown of exposure to PFA on certain aspects of lung function. The relation between exposure and $x$ ray changes is less certain.

Other epidemiological studies indicate that prolonged inhalation of a variety of dusts - for example, in mines, steel foundries, cement works, and textile mills leads to an increase in prevalence of cough and sputum which may be associated with a slight decrement in ventilatory capacity. ${ }^{14}$ The findings described in this cross sectional survey suggests that exposure to PFA has similar effects and that all appropriate measures should be taken to ensure that exposures to PFA do not exceed the limits recommended by the Health and Safety Executive for low toxicity dusts. ${ }^{15}$ Follow up studies would clarify further the nature and extent of any health risk.

We acknowledge the support of Dr J A Bonnell, Mr J Dent, Mr G N Stone, the power station managers, and staff representatives and the help of the Medical Branch nursing officers, the power station administrative officers, and site services engineers and chemists. We would particularly like to thank all those employees and retired members of staff who participated in the survey. We also thank Dr Bennett who organised $x$ ray examinations under the auspices of the NCB $x$ ray service and who also read the $x$ ray films 
with Professor Turner-Warwick and Dr I Kerr. Dr D P Evans, Dr A Newman-Taylor, and Dr R Cartwright all contributed ideas and suggestions. Special thanks are due to Mrs J Taylor who acted as administrator and liaison officer with the power stations in addition to typing the drafts.

Requests for reprints to: Dr C J Schilling, CEGB, Bankside House, Sumner Street, London SE1 9JU.

\section{References}

1 Raask E. Quartz sulphates and trace elements in PF ash. Journal of the Institute of Energy 1980;70:71-5.

2 Raask E, Schilling CJ. Research findings on the toxicity of quartz particles relevant to pulverized fuel ash. Ann Occup Hyg 1980;23:147-57.

3 Bonnell JA, Raask E, Whitehead A. Toxicity tests of pulverised fuel ash. London: CEGB, 1978. (Nuclear health \& safety report 147.)

4 Hill JO, Hobbs CH. Comparative cytotoxicity of DQ 12 quartz and fly ash particles from coal combustion. Toxicol Lett 1982;10:399-403.

5 McFarland HN, Ulrigh CE, Martin A, Drumm A, Bush WM, Alarie Y. Chronic exposure of cynamologous monkeys to fly ash. In: Walton WH, ed. Inhaled particles III. Old Woking: Unwin Brothers Ltd, 1971:313-26.

6 Raabe OG, Tyler WS, Last JA, et al. Studies of the chronic inhalation of coal fly ash by rats. In: Walton WH, ed. Inhaled particles V. Oxford: Pergamon Press, 1982:189-209.

7 Bonnell JA, Schilling CJ, Massey PMO. Clinical and experimental studies of the effects of pulverised fuel ash-a review. Ann Occup Hyg 1980;23:159-64.

8 Gardner RM, Hankinson JL, Blaw JW. Evaluating commercially available spirometers. Am Rev Respir Dis 1980;121:73.

9 American Thoracic Society Snowbird workshop on the standardisation of spirometry. Am Rev Respir Dis 1979;119:831-8.

10 Ogilvie CM, Forster RE, Blackemore WS, et al. A standardized breath holding technique for the clinical measurement of the diffusing capacity of the lung for carbon monoxide. J Clin Invest 1957;36:1-17.

11 International Labour Office. Guidelines for the use of ILO international classification of radiographs of pneumoconiosis. Geneva: ILO, 1980. (Occupational safety health series No 22 (rev 80).)

12 Fletcher CM. The clinical diagnosis of pulmonary emphysema. Proceedings of the Royal Society of Medicine 1952;45:577-84.

13 Davison AG, Durham S, Newman-Taylor AJ, Schilling CJ. Asthma caused by pulverised fuel ash-case report. $\mathrm{Br}$ Med J 1986;292:1561.

14 Morgan WKC. Industrial bronchitis. $\mathrm{Br} J$ Ind Med 1978;35: 285-91.

15 Health and Safety Executive. Occupational exposure limits 1986. London: HSE 1986. (Guidance Note: EH 40/86.)

\section{Destruction of manuscripts}

From 1 July 1985 articles submitted for publication will not be returned. Authors whose papers are rejected will be advised of the decision and the manuscripts will be kept under security for three months to deal with any inquiries and then destroyed. 